\title{
Surface morphology of Ni-Fe thin films grown on copper substrates using pulse electrodeposition in ultrasonic field
}

\begin{abstract}
Nickel-Iron $(\mathrm{Ni}-\mathrm{Fe})$ thin films were pulse-electrodeposited on copper $(\mathrm{Cu})$ substrates under galvanostatic mode in the presence/absence of an ultrasonic field. The as-prepared thin films were characterized by X-Ray Diffractometer (XRD) and Scanning Electron Microscopy (SEM). The XRD results confirmed the deposition of $\mathrm{NiFe}$ on $\mathrm{Cu}$ substrates and the crystallite size calculated from Scherrerpsilas formula is $22.28 \mathrm{~nm}$ and $20.17 \mathrm{~nm}$ respectively for the films fabricated in the absence and presence of ultrasonic field. The grain sizes, from SEM micrographs, were found to be $225.52 \mathrm{~nm}$ and $79.64 \mathrm{~nm}$ respectively for the films fabricated in the absence and presence of ultrasonic field and the grains were in the shape of spherical balls.
\end{abstract}

